This is an electronic reprint of the original article. This reprint may differ from the original in pagination and typographic detail.

\author{
Author(s): von Bonsdorff, Mikaela; Leinonen, Raija; Kujala, Urho; Heikkinen, Eino; Törmäkangas, \\ Timo; Hirvensalo, Mirja; Rasinaho, Minna; Karhula, Sirkka; Mänty, Minna; Rantanen, \\ Taina
}

Title: $\quad$ Effect of physical activity counseling on home care use in older people

Year: $\quad 2009$

Version:

Please cite the original version:

von Bonsdorff, M., Leinonen, R., Kujala, U., Heikkinen, E., Törmäkangas, T., Hirvensalo, M., Rasinaho, M., Karhula, S., Mänty, M., \& Rantanen, T. (2009). Effect of physical activity counseling on home care use in older people. Journal of the American Geriatrics Society, 57(3), 571-573. https://doi.org/10.1111/j.15325415.2009.02163.x

All material supplied via JYX is protected by copyright and other intellectual property rights, and duplication or sale of all or part of any of the repository collections is not permitted, except that material may be duplicated by you for your research use or educational purposes in electronic or print form. You must obtain permission for any other use. Electronic or print copies may not be offered, whether for sale or otherwise to anyone who is not an authorised user. 


\section{Effect of Physical Activity Counseling on Home Care Use among Older People}

Mikaela B. von Bonsdorff, MSc, ${ }^{*}$ Raija Leinonen, $\mathrm{PhD},{ }^{\dagger}$ Urho M. Kujala, MD, $\mathrm{PhD},{ }^{\star}$ Eino Heikkinen, MD, PhD, ${ }^{*}$ Timo Törmäkangas, MSc, ${ }^{*}$ Mirja Hirvensalo, $\mathrm{PhD},{ }^{\S}$ Minna Rasinaho, MSc, ${ }^{\S}$ Sirkka Karhula, BSociol, ${ }^{\mathbb{I}}$ Minna Mänty, MSc, ${ }^{*}$ Taina Rantanen, PhD*

From the:

*Finnish Centre for Interdisciplinary Gerontology, Department of Health Sciences, University of Jyväskylä, Finland; ${ }^{\dagger}$ GeroCenter Foundation for Research and Development, Jyväskylä, Finland;

${ }^{\dagger}$ Department of Health Sciences, University of Jyväskylä, Finland; ${ }^{\S}$ Department of Sport Sciences, University of Jyväskylä, Finland; and ${ }^{\mathbb{T}}$ Centre for Social and Health Services, City of Jyväskylä, Finland

\section{Corresponding author:}

Mikaela von Bonsdorff

Finnish Centre for Interdisciplinary Gerontology

University of Jyväskylä

PO Box 35 (Viveca)

FIN-40014 University of Jyväskylä

Tel. +358 14260 4596, Fax +358 14260 4600, E-mail mikaela.bonsdorff@ sport.jyu.fi

Word count of the paper: 746

References: 8

Figures: 1 


\section{To the Editor:}

The high prevalence of disability among older sedentary people increases the need for home care services, ${ }^{1-3}$ thus interventions for postponing disability and related service use are urgently needed. ${ }^{4}$ A recent randomized controlled trial (RCT) showed that physical activity counseling decreased functional limitations among older people. ${ }^{5}$ In addition, subgroup analyses showed a reduction in the incidence of instrumental activities of daily living (IADL) disability for those without IADL disability at baseline. ${ }^{6}$ This paper presents results on the effect of physical activity counseling on formal home care use among older community-dwelling sedentary persons. 


\section{METHODS}

The design and methodology of the Screening and Counseling for Physical Activity and Mobility (SCAMOB) project have been reported in detail elsewhere. ${ }^{7}$ SCAMOB was a 2-year, singleblinded, randomized controlled trial with 1.5-year follow-up on the effects of individualized physical activity counseling for older sedentary people. The target population consisted of all 7581-year-old registered residents of the City of Jyväskylä, Finland living in the city centre area in March 2003 (N=1310). After a four-phased screening and data collection process, 632 persons were found to be eligible for the study. The Ethical Committee of the Central Finland Health Care District approved the study, ISRCTN is 07330512.

The intervention group received one individual motivational face-to-face physical activity counseling session by one physiotherapist specifically trained for the task. ${ }^{7}$ This was followed up by telephone contact every four months for two years and two annual lectures on physical activity to support compliance and behavior change. Control group received no intervention.

Home care was defined as using publicly subsidized formal home help or home nursing for various activities at least once a month for at least three months. Home care activities included e.g. help in IADL and self-care tasks such as bathing, shopping, and preparing food. Hazard ratios (HR) and 95\% confidence intervals (CI) on home care use were estimated using Cox proportional hazards model. Statistical significance was set at $\mathrm{P}<0.05$. 


\section{RESULTS}

632 persons were randomized into an intervention $(n=318)$ or control group $(n=314)$. Of these, 567 (90\%) persons gave written consent to collect data from the City of Jyväskylä health and social service register on home care use during the 2-year trial and 1.5-year follow-up. We excluded 3 persons, who used formal home care at baseline. Of these 564 (intervention $n=290$ and control group $n=274$ ) persons, 59\% managed self-care tasks such as bathing, getting out of bed and toileting without difficulty whereas of those RCT participants that we did not investigate $(n=68)$, $42 \%$ managed the tasks without difficulty $(\mathrm{p}=0.01)$.

Baseline characteristics of the intervention and control groups were comparable, except that in the intervention group $61 \%$ and control group $51 \%$ lived alone $(\mathrm{p}=0.01)$. In both groups the majority of participants were women (76\%), mean age was 77.6 (SD 1.95) years, they had on average three chronic diseases, and $68 \%$ were able to walk $2 \mathrm{~km}$ without difficulties. In the intervention group $15 \%$ and in the control group $18 \%$ received informal care from a spouse, child or relative. The risk for home care use was about $50 \%$ lower for the intervention group compared to the control group (see Figure 1). 


\section{DISCUSSION}

The current secondary analyses of the RCT data suggest that physical activity counseling may help reduce the need for home care in the long term. It was hypothesized that physical activity counseling increases physical activity, which in turn, decreases mobility difficulties, postpones disability, and consequently decrease the need for home care. The current results complement the earlier findings on reduced mobility limitation ${ }^{5}$ and the subgroup finding on reduced incident IADL disability ${ }^{6}$ and indicate that the trial benefits may extend the entire length of the hypothesized pathway.

The use of other forms of care did not explain the treatment effect. At baseline and follow-up, about $10 \%$ of the participants in both trial groups reported using private home care services. Informal care did not differ significantly between the groups at baseline or in follow-up. None of the participants were institutionalized at baseline and during the 3.5-year period only one person from the control group was institutionalized without prior home care use.

Register-based data was used for investigating the use of publicly subsidized home care, which eliminated the effect of reporting bias. ${ }^{8}$ Home care data were available for $90 \%$ of the RCT participants, which is why the effect of randomization is uncertain. However, the findings indicate that there is a growing need for interventions aiming to increase physical activity for older people with follow-up on the need of health and social services. 


\section{Conflicts of interest:}

All authors declare no interest of conflict.

\section{Grant Support:}

The study was funded by the Finnish Ministry of Education; the Finnish Ministry of Social Affairs and Health; Juho Vainion Foundation; Yrjö Jahnsson Foundation, the Finnish Cultural Foundation.

\section{Role of the sponsor:}

The funding sources of the study had no role in the design, implementation or analyses of the data or in the preparation of the manuscript for publication.

\section{Author Contributions:}

E. Heikkinen, T. Rantanen, R. Leinonen originated the study and obtained the funding. M.B. von Bonsdorff and T. Rantanen analyzed and interpreted the data. M.B. von Bonsdorff drafted the paper. T.Rantanen, U.M. Kujala, E. Heikkinen critically revised the paper. M. Hirvensalo and M. Rasinaho were responsible for the physical activity counseling intervention. R. Leinonen, M.B. von Bonsdorff, M. Mänty, and S. Karhula participated in data collection. T. Törmäkangas was the statistical expert. All authors contributed to the intellectual content of the paper and approved the final version. 


\section{REFERENCES}

1. Kemper P. The use of formal and informal home care by the disabled elderly. Health Serv Res 1992;27:421-451.

2. Langa KM, Chernew ME, Kabeto MU et al. The explosion in paid home health care in the 1990s: who received the additional services? Med Care 2001;39:147-157.

3. Kadushin G. 2004. Home health care utilization: a review of the research for social work. Health Soc Work 2004;29:219-244.

4. Penninx BWJH, Messier SP, Rejeski $\mathrm{J}$ et al. Physical exercise and the prevention of disability in activities of daily living in older persons with osteoarthritis. Arch Intern Med 2001;161:2309-2316.

5. Mänty M, Heinonen A, Leinonen R et al. Long-term effect of physical activity counseling on the development of mobility limitation among older people: a randomized controlled study. J Gerontol A Biol Sci Med Sci in press.

6. von Bonsdorff MB, Leinonen R, Kujala UM et al. Effect of Physical Activity Counseling on Disability among Older People: A 2-year RCT. J Am Geriatr Soc DOI: 10.1111/j.15325415.2008.02000.x 
7. Leinonen R, Heikkinen E, Hirvensalo $M$ et al. Customer-oriented counseling for physical activity in older people: study protocol and selected baseline results of a randomized controlled trail (ISRCTN 07330512) Scand J Med Sci Sports 2007;17:156-164.

8. Wallihan DB, Stump TE, Callahan CM. Accuracy of self-reported health services use and patterns of care among urban older adults. Med Care 1999;37:662-670. 
Legend for Figure 1:

Cumulative incidences, person-years, hazard ratios (HR) and 95\% confidence intervals (CI) for home care use during the 2-year intervention and 3.5 intervention and follow-up time among the intervention and control group 
Figure 1:

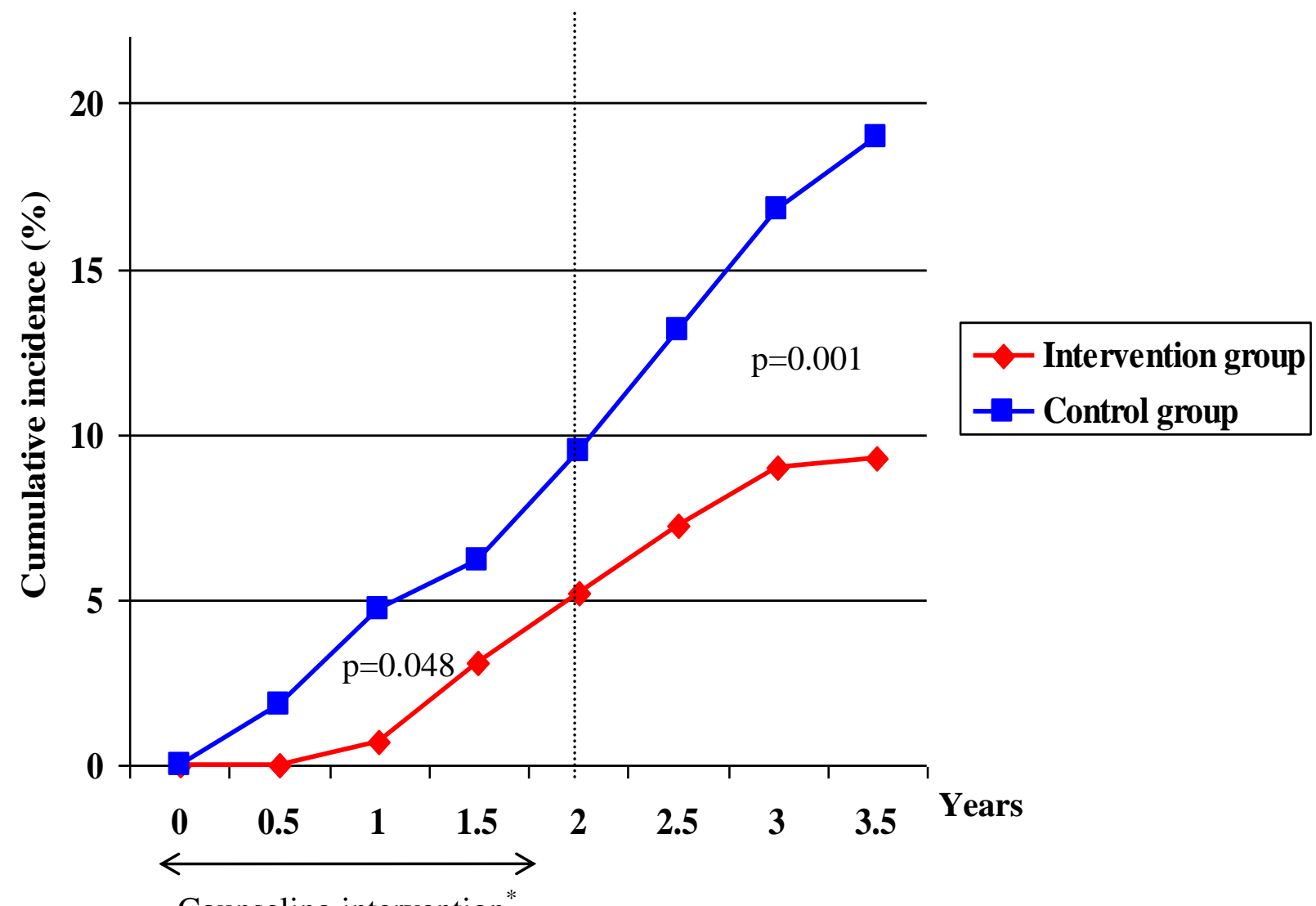

Counseling intervention

Counseling intervention and follow-up ${ }^{\dagger}$

Comparisons made with chi-square test

* 2-year intervention: in intervention group 15 persons (2.6/100 person-years) and in control group 26 persons (5.0/100 person-years) started using home care, $\mathrm{HR}=0.51,95 \% \mathrm{CI} 0.27-0.97$. The model was adjusted with age, gender and living alone.

$\dagger 3.5$-year period: in intervention group 27 persons (2.8/100 person-years) and in control group 52 persons (6.0/100 person-years) started using home care, $\mathrm{HR}=0.51,95 \% \mathrm{CI} 0.27-0.97$. The model was adjusted with age, gender and living alone. 